\title{
Relationship between Cerebral Activity and Movement Frequency of Maximal Finger Tapping
}

\author{
Naomi Kuboyama ${ }^{1)}$, Teru Nabetani ${ }^{2)}$, Kenichi Shibuya ${ }^{3)}$, Keishi Machida ${ }^{4)}$ and Tetsuro Ogaki ${ }^{1,5)}$ \\ 1) Graduate School of Human Environment Studies, Kyushu University \\ 2) Department of Contemporary Communication, Shizuoka Eiwa Gakuin University Junior College \\ 3) Department of Sports Science, Japan Institute of Sports Science \\ 4) Hitachi Medical Co. Ltd., Tokyo \\ 5) Institute of Health Science, Kyushu University
}

\begin{abstract}
To examine the cerebral activity of the motor cortex during maximum movement, we measured regional cerebral blood flow (rCBF) in twelve normal volunteers, using near infrared spectroscopy (NIRS). Repetitive tapping of the right index finger was performed at 1.0, 1.5, 2.0, 2.5, 3.0, 3.5, 4.0 , and $4.5 \mathrm{~Hz}$, and during maximum effort (ME). The relative increase rate of $\mathrm{rCBF}$ during movement beginning with a resting condition was calculated for each movement condition. The left primary sensorimotor cortex showed significant activation during ME compared to the other frequencies. The rapid increase of $\mathrm{rCBF}$ was seen immediately after the initiation of finger tapping at all the tested frequencies but showed no increase following that. However, the rCBF during ME continued to increase until the end of the task.

Change of the integrated electromyogram (iEMG) for the frequency and change of $\mathrm{rCBF}$ for the frequency at all the tested frequencies showed similar tendencies. $J$ Physiol Anthropol Appl Human Sci 24(3): 201-208, 2005 http:// www.jstage.jst.go.jp/browse/jpa
\end{abstract}

[DOI: 10.2114/jpa.24.201]

Keywords: near infrared spectroscopy (NIRS), motor cortex, tapping, regional cerebral blood flow ( $\mathrm{rCBF}$ ), electromyogram (EMG)

\section{Introduction}

Studies in humans through the use of positron emission tomography (PET) and rCBF signal changes as an indirect index of brain activity have explored the effect of stimulus rate on the central nervous system, particularly in the primary visual cortex (Fox and Raichle, 1984). The rCBF change in the striate cortex is proportional to the repetition rate of photic stimulation between 0 and $7.8 \mathrm{~Hz}$ (Fox and Raichle, 1984). In other studies, a linear relationship was also observed in the primary auditory cortex (Wise et al., 1991; Price et al., 1992). These studies underscore the significance of the stimulus rate as a determinant of $\mathrm{rCBF}$ response. Moreover, research has also been conducted on the relationship between frequency and rCBF using a movement stimulus (Sadato et al., 1996; Jenkins et al., 1997).

Jenkins et al. (1997) examined the effect of joystick movement, in frequencies that ranged from $1 / \mathrm{sec}$ to 1 every $5.5 \mathrm{sec}$ in $0.5 \mathrm{~s}$ steps, on cerebral activation. They observed no significant relationship between movement frequency and cerebral activation. Furthermore, Sadato et al. (1997) measured rCBF by PET and reported that the relationship between motor cortex activation and movement frequency was not significant, and tended to plateau as the frequency reached $4 \mathrm{~Hz}$.

In these studies, cerebral activation showed a nonlinear increase, indicating an exponential rise. Thus, the relationship between stimulus frequency and brain activity differs in terms of the region of the brain and the type of stimulation. In brain activity studies using movement stimulus, movement was restricted by the limitations of the test equipment and was not performed with high frequency stimuli of over $4.0 \mathrm{~Hz}$. Due to noise interference while the body is being measured, measurement of movements of high frequency is impossible.

For this reason, the relationship between a movement stimulus and $\mathrm{rCBF}$ has not been examined at high frequencies (over $4.0 \mathrm{~Hz}$ ).

Therefore, brain activity at high frequencies is still unknown. It is important to know the reaction of rCBF for the frequency so that the mechanism of movement can be evaluated.

Changes in cerebral hemodynamics and oxygenation can be measured using several techniques. For example, positron emission tomography (PET) or tracer methods such as ${ }^{133} \mathrm{Xe}$ single photon emission computer tomography (SPECT) have been used to measure changes in rCBF. These methods, however, are associated with the injection of radioactive 
compounds, and have a low temporal resolution (Villringer, 1997). Transcranial Doppler (TCD) sonography has been used to monitor changes in blood flow velocity in the large cerebral arteries. This method has a high degree of temporal resolution, but does not provide information regarding regional changes in cerebral oxygen supply or metabolism (Hirth et al., 1997; Vernieri et al., 1999).

On the other hand, studies using NIRS and functional magnetic resonance imaging (fMRI) allow non-invasive monitoring of regional changes in cortical tissue oxygenation in response to various stimuli including visual, auditory, and exercise stimuli (Colier et al., 1997, 1999; Kleinschmidt et al., 1996; Mehagnoul-Schipper et al., 2000; Obrig et al., 1996, 2000; Rao et al., 1993; van der Kallen et al., 1998).

The fMRI and the PET methods are vulnerable to movement artifacts and limitations in monitoring changes in cerebral oxygenation during dynamic movement. On the other hand, NIRS has an advantage in that it permits specific monitoring of changes in oxy-hemoglobin (oxy-Hb), deoxy-hemoglobin (deoxy-Hb), and total-hemoglobin (total-Hb) with high temporal resolution even during dynamic movement (Colier et al., 1997). Therefore, in order to measure brain activity at high movement frequencies, including maximum effort (ME), it is necessary to use NIRS.

In regard to the relationship between brain activity and muscle output, Dettmers et al. (1995) reported a direct relationship between the index finger flexion force and increases in cerebral blood flow in four motor-related brain regions: the contralateral sensorimotor cortex, the supplementary motor area, the cingulate cortex, and the cerebellum. Based on single-cell recordings taken in the primary motor cortex in monkeys, a direct relationship between the neuronal discharge rate and exerted force has been reported (Evarts, 1968; Hepp-Reymond et al., 1978, 1999).

These findings suggest that brain activity and cerebral blood flow are directly related to muscle output. Thus, in order to elucidate the true relationship between movement frequency and brain activity, it is necessary to measure muscle activity simultaneously.

The purpose of the present study was to observe the value of brain hemoglobin at ME which has not previously been investigated. Simultaneously, muscle activity was measured using EMG, and it was examined and compared with brain activity.

\section{Method}

\section{Subjects}

Five men and seven women, ranging in age from 22 to 37 years $[25.9 \pm 4.9($ mean $\pm S D)$ years] participated. All of them were right-handed as indicated by self-report. All subjects were healthy and had no known neuromuscular disorders. All subjects gave informed consent prior to participation in the study.

\section{Motor tasks}

The subjects sat in a chair and were asked to press a button on the table repetitively with their right index finger. Cerebral activation was measured by NIRS during finger tapping. To investigate the effect of movement frequency on cerebral activation, subjects were randomly divided into two groups between which there were no differences. In the low frequency group, the finger tapping frequencies were performed at 1.0, $1.5,2.0,2.5,3.0 \mathrm{~Hz}$, and at ME. In the high-frequency group, the finger-tapping frequencies were performed at 2.5, 3.0, 3.5, $4.0,4.5 \mathrm{~Hz}$ and at ME. In both groups, the experimental order of frequencies was randomized. Finger tapping in the range of $1.0 \mathrm{~Hz}$ to $4.5 \mathrm{~Hz}$ was regulated by the sound of an electrical metronome (average achievement ratio: 89\%). Each of the finger-tapping cycles lasted $20 \mathrm{~s}$, followed by a $40 \mathrm{~s}$ rest period. Three cycles were performed. The rCBF of the left primary motor cortex was measured by NIRS throughout the three cycles.

\section{Near infrared spectroscopy (NIRS)}

NIRS, a new noninvasive optical technique, measures changes in concentrations of oxygenated and deoxygenated hemoglobin (oxy- $\mathrm{Hb}$ and deoxy- $\mathrm{Hb}$, respectively) mainly in cerebral venous blood. Summation of the changes in oxy-Hb and deoxy-Hb indicates changes in the total hemoglobin concentration (total- $\mathrm{Hb}$ ). The change in total-Hb can be used as a measure of blood volume changes (Delpy et al., 1988).

The 24-channel two-wavelength NIRS system (ETG-100; Hitachi Medical Corporation, Tokyo, Japan) (Koizumi et al., 1999) has eight light-incident and eight detector fibers. The light sources were $0.5 \mathrm{~mW}$ continuous laser diodes with wavelengths of 780 and $830 \mathrm{~nm}$. Oscillators were used to modulate the intensity of each diode to within the range of 1.0 to $4.9 \mathrm{kHz}$ in order to prevent cross-talk between the channels and the wave length (Maki et al., 1995). The optodes were positioned over the left motor cortex enclosing $\mathrm{C} 3$ according to the 10 to 20 system for standard electrode positions (American Electroencephalographic Society, 1994).

The optodes were attached to a tight elastic headband in order to press them against the scalp. Changes in total-Hb, oxy- $\mathrm{Hb}$, and deoxy-Hb were sampled every $0.1 \mathrm{~s}$ and stored on a floppy disk for offline analysis by a computerized system. Before the beginning of the protocol, the oxygenation response was checked for $20-\mathrm{s} 2 \mathrm{~Hz}$ finger tapping. If no oxygenation change could be detected, the optodes were moved, less than $1 \mathrm{~cm}$, until a response was signaled (Colier et al., 1997).

\section{Electromyography (EMG) signal}

Surface EMG was recorded from the extensor digitorum and flexor carpi radialis during finger tapping. Bipolar electrodes ( $4 \mathrm{~mm}$ in recording diameter) were attached to the skin overlaying the muscle in the forearm with a reference electrode. The muscles were identified by palpating the skin surface while the subject moved the index finger. The EMG signal was recorded during finger tapping at different 
frequencies. The EMG signal was digitized at a rate of 1000 samples/s and saved onto the hard disk of a personal computer for off-line analysis. The EMG was rectified and averaged over a 500-ms period when the EMG was greatest.

\section{Statistical analysis}

All parameters are described by mean \pm SD. The NIRS time trend was analyzed by repeated measures ANOVA, with the Bonferroni correction for post-hoc tests. $p<0.05$ was considered statistically significant.

\section{Results}

There were no significant differences in maximal finger tapping scores between the low frequency group and the high frequency group subjects.

The finger-tapping task at $\mathrm{ME}$ was $5.7 \pm 0.5 \mathrm{~Hz}$ in the low frequency group, and was $6.6 \pm 0.9 \mathrm{~Hz}$ in the high frequency group. The finger tapping caused activity in the motor cortex in all frequencies.

In the low frequency group, no significant increases in total$\mathrm{Hb}$, oxy- $\mathrm{Hb}$, and deoxy- $\mathrm{Hb}$ were seen from $1.0 \mathrm{~Hz}$ to $3.0 \mathrm{~Hz}$. In the high frequency group, no significant increases in total- $\mathrm{Hb}$, oxy- $\mathrm{Hb}$, and deoxy-Hb were seen from $2.5 \mathrm{~Hz}$ to $4.5 \mathrm{~Hz}$.

As for the total-Hb during $\mathrm{ME}$, both groups (high: $0.386 \pm 0.049 \mathrm{mmol} * \mathrm{~mm}, \quad$ low: $\quad 0.301 \pm 0.048 \mathrm{mmol} * \mathrm{~mm}$ ) showed significantly high values compared with those at other frequencies $(p<0.01)$. Oxy-Hb (high: $0.343 \pm 0.037 \mathrm{mmol} * \mathrm{~mm}$, low: $0.300 \pm 0.021 \mathrm{mmol} * \mathrm{~mm}$ ) also showed similar trends. In the low frequency group, deoxy-Hb showed no significance. In the high frequency group, deoxy- $\mathrm{Hb}(0.023 \pm$ $0.015 \mathrm{mmol} * \mathrm{~mm})$ at $\mathrm{ME}$ showed significantly high values compared with those at other frequencies $(p<0.05)$. Table 1 and Fig. 1 summarize the results of the increase of oxy-Hb, deoxy- $\mathrm{Hb}$, and total- $\mathrm{Hb}$ in relation to their baseline values in the low frequency group and the high frequency group.

Table 1 Average changes in oxy-hemoglobin ([oxy-Hb]), deoxy-hemoglobin ([deoxy-Hb]), and total hemoglobin ([total-Hb]) concentrations as measured from their baseline values by NIRS over the left motor cortex, and average changes in electromyographic (EMG) over muscle of extensor digitorum (ED) and muscle of flexor carpi radialis (FCR) at 1.0, 1.5, 2.0, 2.5, 3.0 Hz and ME (5.7 Hz) during $20 \mathrm{~s}$ finger tapping task in the low frequency group.

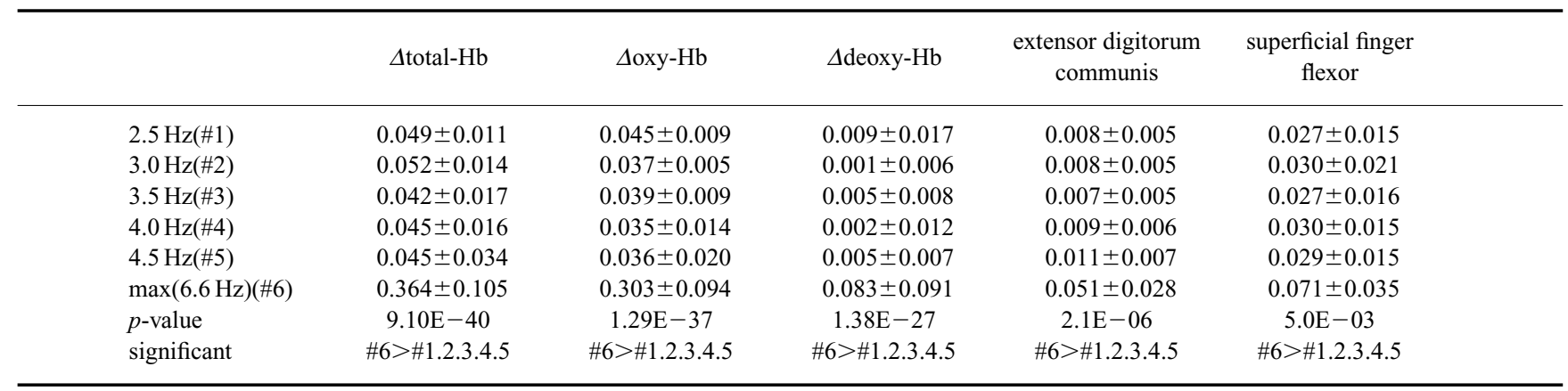

The increase of [total-Hb] and [oxy-Hb] at ME from their baseline values were significantly higher than other frequencies $(p<0.01)$. EMG at ME were significantly higher than other frequencies $(p<0.01)$. Data are presented as mean \pm SD. $* *$ Significantly changes from base line value $(p<0.01)$.

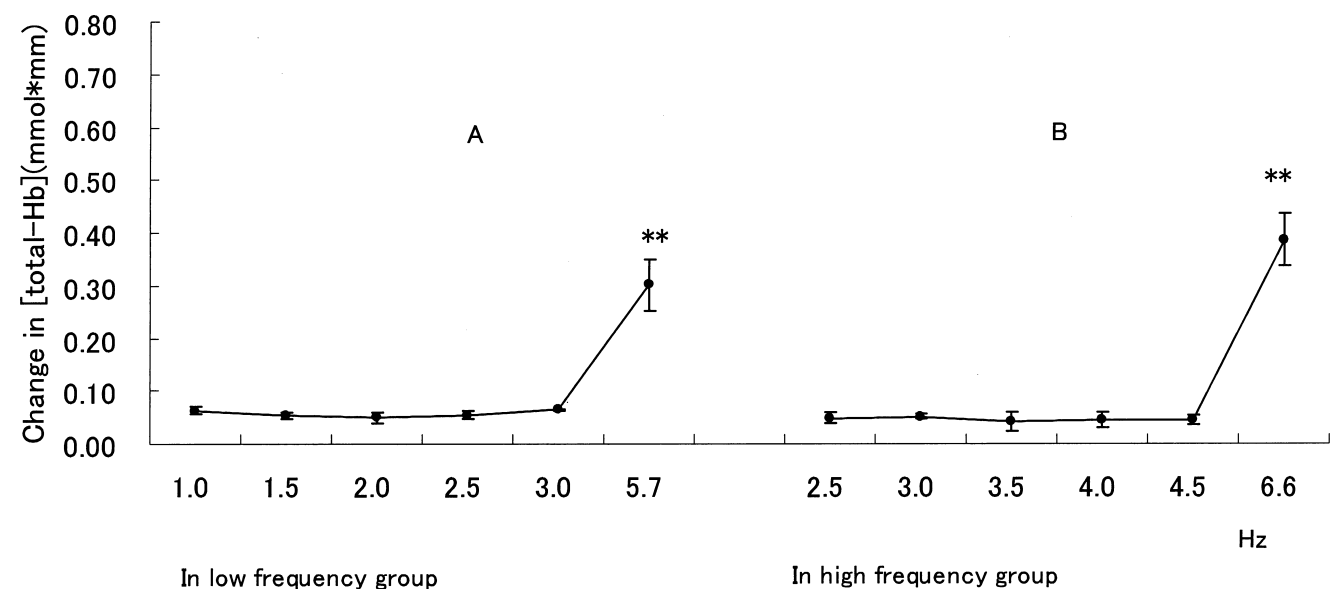

Fig. 1 A: In the low frequency group, change in total hemoglobin [total-Hb] concentrations as measured by NIRS over the left motor cortex in healthy subjects $(\mathrm{n}=6)$ during a 20 -sec contralateral finger tapping task. Total- $\mathrm{Hb}$ at $\mathrm{ME}(5.7 \pm 0.5 \mathrm{~Hz})$ shows significantly high values compared with those at other frequencies $(p<0.01)$. ** Significantly changes form base line value. Data are presented as mean \pm SD.

$\mathrm{B}$ : In the high frequency group, change in total hemoglobin [total-Hb] concentrations as measured by NIRS over the left motor cortex in healthy subjects $(\mathrm{n}=6)$ during a 20 -sec contralateral finger tapping task. Total- $\mathrm{Hb}$ at $\mathrm{ME}(6.6 \pm 0.9 \mathrm{~Hz})$ shows significantly high values compared with those at other frequencies $(p<0.01)$. ** Significantly changes form base line value. Data are presented as mean \pm SD. 
In a change of $\mathrm{rCBF}$ with time course during finger tapping for 20 seconds, an increase of rapid $\mathrm{rCBF}$ was seen in the frequency range of $1.0 \mathrm{~Hz}$ to $4.5 \mathrm{~Hz}$ immediately after the initiation of the finger-tapping task. However, it did not increase afterwards. The total-Hb during $\mathrm{ME}$ increased immediately after the initiation of motion. This increase continued to the end of the finger-tapping task.

Table 2 and Fig. 2 summarize the results of iEMG in the low frequency group and the high frequency group.

The iEMG was not significant in the range of $1.0 \mathrm{~Hz}$ to $4.5 \mathrm{~Hz}$. The iEMG during ME, (extensor digitorum communis: low frequency group $0.026 \pm 0.007 \mathrm{mV}$, high frequency group $0.051 \pm 0.028 \mathrm{mV}$, superficial finger flexor: low frequency group $0.054 \pm 0.026 \mathrm{mV}$, high frequency group $0.071 \pm$
$0.035 \mathrm{mV}$ ) showed values comparable to other frequencies and was significantly high $(p<0.05)$.

\section{Discussion}

We found that the relationship between brain activity and movement frequency was not exponential. The increased rCBF during $\mathrm{ME}$ was significantly higher than at other frequencies, and the increased $\mathrm{rCBF}$ during $\mathrm{ME}$ differed from the exponential nature that the relationship between tapping frequency and brain activation had been reported (Jenkins et al., 1997; Sadato et al., 1996).

Some studies have investigated the relationship between brain activity and movement frequency. In studies using visual

Table 2 Average changes in oxy-hemoglobin ([oxy-Hb]), deoxy-hemoglobin ([deoxy-Hb]), and total hemoglobin ([total-Hb]) concentrations as measured from their baseline values by NIRS over the left motor cortex, and average changes in electromyographic (EMG) over muscle of extensor digitorum (ED) and muscle of flexor carpi radialis (FCR) at 2.5, 3.0, 3.5, 4.0, 4.5 Hz and ME $(6.6 \mathrm{~Hz})$ during $20 \mathrm{~s}$ finger tapping task in the high frequency group.

\begin{tabular}{|c|c|c|c|c|c|}
\hline & $\Delta$ total-Hb & $\Delta$ oxy-Hb & $\Delta$ deoxy-Hb & $\begin{array}{l}\text { extensor digitorum } \\
\text { communis }\end{array}$ & $\begin{array}{l}\text { superficial finger } \\
\text { flexor }\end{array}$ \\
\hline $1.0 \mathrm{~Hz}(\# 1)$ & $0.064 \pm 0.008$ & $0.041 \pm 0.010$ & $0.008 \pm 0.009$ & $0.013 \pm 0.006$ & $0.027 \pm 0.016$ \\
\hline $1.5 \mathrm{~Hz}(\# 2)$ & $0.054 \pm 0.016$ & $0.030 \pm 0.004$ & $0.002 \pm 0.007$ & $0.013 \pm 0.009$ & $0.024 \pm 0.014$ \\
\hline $2.0 \mathrm{~Hz}(\# 3)$ & $0.050 \pm 0.011$ & $0.043 \pm 0.018$ & $0.003 \pm 0.011$ & $0.013 \pm 0.007$ & $0.026 \pm 0.014$ \\
\hline $2.5 \mathrm{~Hz}(\# 4)$ & $0.054 \pm 0.017$ & $0.043 \pm 0.008$ & $0.009 \pm 0.003$ & $0.018 \pm 0.010$ & $0.031 \pm 0.017$ \\
\hline $3.0 \mathrm{~Hz}(\# 5)$ & $0.065 \pm 0.035$ & $0.045 \pm 0.021$ & $0.010 \pm 0.003$ & $0.014 \pm 0.007$ & $0.030 \pm 0.018$ \\
\hline $\max (5.7 \mathrm{~Hz})(\# 6)$ & $0.221 \pm 0.108$ & $0.202 \pm 0.029$ & $0.028 \pm 0.071$ & $0.026 \pm 0.007$ & $0.054 \pm 0.026$ \\
\hline$p$-value & $6.78 \mathrm{E}-42$ & $4.75 \mathrm{E}-47$ & $7.86 \mathrm{E}-13$ & 0.048 & 0.060 \\
\hline significant & $\# 6>\# 1.2 .3 .4 .5$ & $\# 6>\# 1.2 .3 .4 .5$ & $\# 6>\# 1.2 .3 .4 .5$ & $\# 6>\# 1.2 .3 .4 .5$ & N.S \\
\hline
\end{tabular}

The increase of [total-Hb] and [oxy-Hb] at ME from their baseline values were significantly higher than other frequencies $(p<0.01)$. EMG at ME were significantly higher than other frequencies $(p<0.01)$. Data are presented as mean \pm SD. $* *$ Significantly changes from base line value $(p<0.01)$.

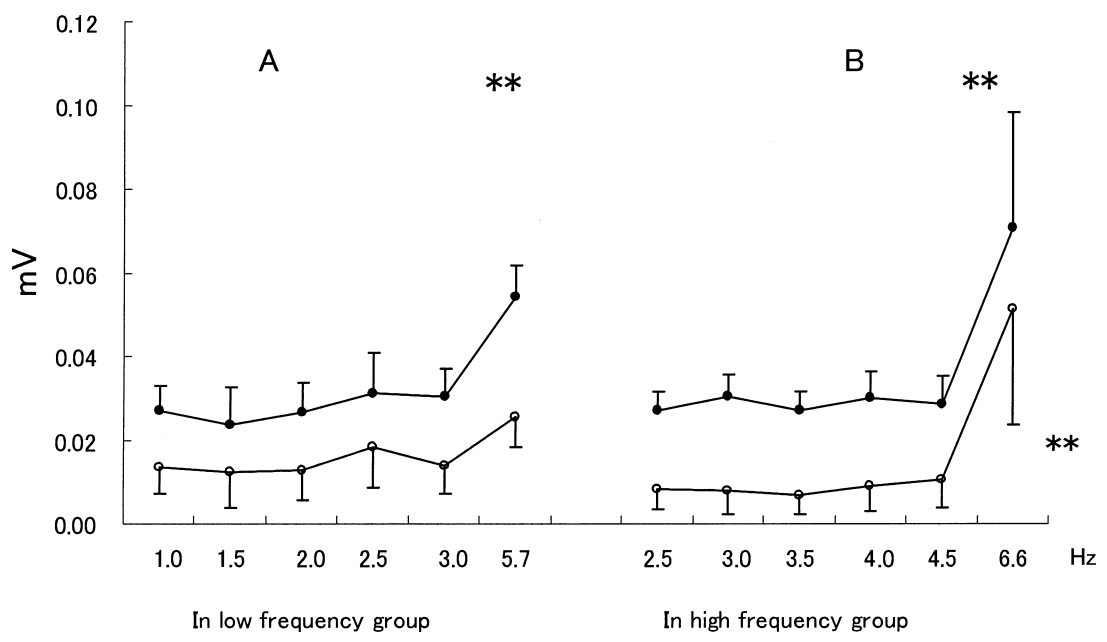

Fig. 2 A: In the low frequency group, change in electromyography (EMG) signal over muscle of extensor digitorum (ED) and muscle of flexor carpi radialis $(\mathrm{FCR})$ in healthy subjects $(\mathrm{n}=6)$ during a 20 -sec right finger tapping task. EMG at $\mathrm{ME}[\mathrm{ED}(-): 0.054 \pm 0.026 \mathrm{mV}$; FCR $(O): 0.026 \pm 0.007 \mathrm{mV}$ ] shows significantly high values compared with those at other frequencies $(p<0.01)$. $* *$ Significantly changes form base line value. Data are presented as mean \pm SD.

$\mathrm{B}$ : In the high frequency group, change in electromyography (EMG) signal over muscle of extensor digitorum (ED) and muscle of flexor carpi radialis (FCR) in healthy subjects $(\mathrm{n}=6)$ during a 20-sec right finger tapping task. EMG at $\operatorname{ME~}[\operatorname{ED}(-)$ : $0.071 \pm 0.035 \mathrm{mV}$; FCR $(O): 0.051 \pm 0.028 \mathrm{mV}$ ] shows significantly high values compared with those at other frequencies $(p<0.01)$. ** Significantly changes form base line value. Data are presented as mean $\pm \mathrm{SD}$. 
stimuli, Fox and Raichle (1984) reported the rCBF change was proportional to the repetition rate of photic stimulation between 0 and $7.8 \mathrm{~Hz}$ in the primary visual cortex. Wise et al. (1991) and Price et al. (1992), who used auditory stimuli, also observed a linear relationship in the primary auditory cortex. Thus, the relationship between visual and auditory stimuli and brain activity was seen to be linear.

The present study used a movement stimulus. The increased rCBF-related frequency range from $1.0 \mathrm{~Hz}$ to $4.5 \mathrm{~Hz}$ was not significant. The rCBF during ME showed a significantly higher value than at other frequencies. The relationship between movement frequency and brain activity was not seen to be linear. Thus, the relationship between movement stimulus and brain activity and that of visual and auditory stimulus differ. That means that the reaction to stimulus is different in terms of brain region.

Some researchers have reported the relationship between movement stimulus frequency and brain activity. Jenkins et al. (1997) observed that the relationship between brain activity and movement frequency is exponential during movement under $1.0 \mathrm{~Hz}$. Sadato et al. (1997) reported that the change in motor cortex activation was not significant, and increased rCBF tended to plateau during movement as the frequency reached $4.0 \mathrm{~Hz}$. On the basis of the above studies ranging from $1.0 \mathrm{~Hz}$ to $4.0 \mathrm{~Hz}$, a range increase of $\mathrm{rCBF}$ was seen immediately after the initiation of movement but showed no increase following that during movement in each frequency. And there was no significant difference in cerebral activation. In the present study in the range from $1.0 \mathrm{~Hz}$ to $4.5 \mathrm{~Hz}$, the results showed that the relationship between movement frequency and brain activity is in agreement with the results reported by Jenkins et al. (1997) and Sadato et al. (1997). In the other words, a range increase of rCBF was seen immediately after the initiation of movement but showed no increase following that during movement in the range from $1.0 \mathrm{~Hz}$ to $4.5 \mathrm{~Hz}$. And there is no significant difference of cerebral activation compare with in each movement frequency. However, change of $\mathrm{rCBF}$ in $\mathrm{ME}$ is clearly different from change of $\mathrm{rCBF}$ under $4.5 \mathrm{~Hz}$. ME has not been previously studied. In ME, rCBF during movement $(20 \mathrm{sec})$ continued to increase till movement was over. And increased $\mathrm{rCBF}$ in $\mathrm{ME}$ has a significantly high value as compared with increased rCBF in other movement frequencies. It could be considered that the reason for the $\mathrm{rCBF}$ during $\mathrm{ME}$ being higher than at other frequencies is due to the difference of muscle activity. In the present study, NIRS and EMG measurements were performed simultaneously. The results showed no difference in the muscle activity range of $1.0 \mathrm{~Hz}$ to $4.5 \mathrm{~Hz}$.

Some researchers have investigated the relationship between muscle activity and brain activity (Dettmers et al., 1995; Dai et al., 2001; Evarts, 1968; Hepp-Reymond et al., 1978, 1999; Siemionow et al., 2000). Dai et al. (2001) determined the relationship between fMRI-measured brain activation and handgrip force, and between fMRI-measured brain signals and the iEMG of finger muscles. They reported that in the primary motor and sensory cortex, the signal intensity and the iEMG increased linearly across the entire range of the force levels tested. Thus, the muscle activity is also equivalent, if the brain activity is equivalent. Because iEMG data from $1.0 \mathrm{~Hz}$ to $4.5 \mathrm{~Hz}$ has no significant difference, muscle activity from $1.0 \mathrm{~Hz}$ to $4.5 \mathrm{~Hz}$ is the same. And cerebral activity from $1.0 \mathrm{~Hz}$ to $4.5 \mathrm{~Hz}$ shows no significant difference. In other words, muscle activity and cerebral activity indicate almost the same though movement frequency increases. The results from $1.0 \mathrm{~Hz}$ to $4.5 \mathrm{~Hz}$ of the present study were agreement with those reported by Dai et al. (2001). However, the iEMG showed significantly higher value at ME than the results of them did at other frequencies. De Luca et al. (1982) reported that a hand and finger muscular main control mechanism were neural discharge rate, and most motor units are mobilized by $50 \%$ of maximum muscle out put. Muscle output in ME may increase slightly as compared with other frequencies. But it is hard to consider an increase in muscle output as remarkable when dealing with an increase in finger tapping frequency. Therefore, we considered that the neural discharge rate mainly affects the increase of iEMG in ME than the number of motor units.

The primary motor cortex at maturity represents the contralateral limb muscles through direct spinal projections and indirect projections through the brain stem (Porter and Lemon, 1993). Classic stimulation studies (Porter and Lemon, 1993) have shown that limb movement representations have a basic somatotopic organization, with distinctive arm and leg areas. Within these areas, there appears to exist a relatively complex organization because an individual muscle can be represented at multiple sites as well as at a single site (Armstrong and Drew, 1984; Donoghue et al., 1992; Sato and Tanji, 1989). These findings suggest that small regions of the primary motor cortex could represent motor synergies (Donoghue et al., 1992; Sanes et al., 1995).

The rCBF measured by NIRS reflects the rCBF of the cortex under the scalp between probes ( $30 \mathrm{~mm}$ in the present study). Therefore, in this study it was not possible to confirm the difference of the number of detailed motor units. However, the difference in activation areas is difficult to determine in vivo since almost identical points are activated during muscle cooperation. In the present study, the results of iEMG analysis showed that changes in the activity of the common digital extensor muscle agreed almost completely with the changes in $\mathrm{rCBF}$. We assume that the value of $\mathrm{rCBF}$ during $\mathrm{ME}$ being higher than during other frequencies is affected by the increase of iEMG due to the increase in the neural discharge rate.

The high frequency group tended to have a higher $\mathrm{rCBF}$ during $\mathrm{ME}$ than the low frequency group. Also, the high frequency group tended to have a higher iEMG than the low frequency group. This is due to the neuronal discharge rate of finger flexor and extensor muscles in the low frequency group being lower than that of the high group (De Luca et al., 1982).

Roland et al. (1980) found the same rCBF for the same frequency $(1 \mathrm{~Hz})$ when the subjects flexed their index fingers 
against a $5.88 \mathrm{~N} / \mathrm{cm}$ spring as when they flexed their index fingers with no power output after having been injected with ${ }^{133} \mathrm{Xe}$ in the internal carotid artery. They suggested that the increase of $\mathrm{rCBF}$ in the motor cortex depended less on the increase of muscle power output than on the increase of movement frequency. Because the neural discharge rate and number of mobilization of motor unit become high with an increase of power output, muscle does activity. Compared with no power output, power output is clearly high for muscle activity in the same frequency. That is to say, we consider that degree of muscle activity is a main factor of brain activity. Therefore, muscle output alone is not a factor of brain activity.

As stated earlier, some studies have reported that auditory stimulus increases brain activity (Wise et al., 1991; Price et al., 1992). In the present study, the frequency of finger tapping in the range of $1.0 \mathrm{~Hz}$ to $4.5 \mathrm{~Hz}$ was regulated by the sound of an electrical metronome. It is possible that increased $\mathrm{rCBF}$ in the range of $1.0 \mathrm{~Hz}$ to $4.5 \mathrm{~Hz}$ indudes an increased volume of rCBF from the effect of auditory stimulus. Even if rCBF is increased by an auditory stimulus, there will be little effect. There is not only because the region of measurement is the motor cortex and not the auditory cortex, but also because there is no significant difference of increased $\mathrm{rCBF}$ in the range of $1.0 \mathrm{~Hz}$ to $4.5 \mathrm{~Hz}$. In a study of audio-initiated hand movement by monkeys, Gemba and Sasaki (1987) found that the field potentials in the prefrontal cortex were relatively small after repeated training, but increased temporarily when the frequency of the auditory stimulus was changed. Those researchers suggested that when the monkey devoted intensive attention to auditory stimuli, a large potential appeared in the prefrontal cortex. In a human study using PET (Pardo et al., 1991), the prefrontal cortex area on the right appeared to be related to sustained attention to sensory input. The cingulated cortex has a reciprocal connection with the prefrontal cortex (Pandya et al., 1981). Paus et al. (1993) speculated that the anterior cingulated gyrus may contribute to the funneling of cognitive commands from the prefrontal cortex to the motor cortex, facilitating the execution of the appropriate responses and suppressing inappropriate ones. However, in the present study, we did not adopt an external auditory stimulus during ME. The apparent rise in cerebral activity during ME was not affected by the auditory cue.

As a subject for further research, it is necessary to examine the relationship between movement frequency and the extent of the region activated in the brain.

\section{Conclusion}

We conclude that during maximum effort, the level of neuron discharge of the muscle is high, and that the regional brain blood flow volume is also high in the motor cortex.

\section{References}

American Electroencephaligraphic Society (1994) Guideline thirteen: guideline for standard electrode position nomenclature. J Clin Neurophysiol 11: 111-113

Armstrong DM, Drew T (1984) Topographical localization in the motor cortex of the cat for somatic afferent responses and evoked movements. J Physiol (Lond) 350: 33-54

Butler EG, Horne MK, Churchward PR (1992) A frequency analysis of neuronal activity in monkey thalamus, motor cortex and electromyograms in wrist oscillations. J Physiol (Lond) 445:49-68

Colier WNJM, Quaresima V, Brattelli G, Cavallari P, van der Sluijs M, Ferrari M (1997) Detailed evidence of cerebral hemoglobin oxygenation changes in response to motor activation revealed by a continuous wave spectrophotometer with $10 \mathrm{~Hz}$ temporal resolution. Proc SPIE 2979: 390-396

Colier WNJM, Quaresima V, Oeseburg B, Ferrari M (1999) Human motor-cortex oxygenation change induced by cyclic coupled movements of hand and foot. Exp Brain Res 129: $457-461$

Dai TH, Liu JZ, Sahgal V, Brown RW, Yue GH (2001) Relationship between muscle output and functional MRImeasured brain activation. Exp Brain Res 140: 290-300

De Luca CJ, LeFeever RS, McCue MP, Xenakis AP (1982) Control scheme governing concurrently active human motor units during voluntary contractions. J Physiol 329: 129-142

Deply DT, Cope M, van der Zee P, Aguirre GK, Wray S, Wyatt J (1998) Estimation of optical pathlength through tissue from direct time of flight measurement. Phys Med Bio 33: 1433-1442

Dettmers C, Fink GR, Lemon RN, Stephan KM, Passingham RE, Silbersweig D, Holmes A, Ridding MC, Brooks DJ, Frackowiak RS (1995) Relationship between cerebral activity and force in the motor areas of the human brain. J Neurophysiol 74: 802-815

Donoghue JP, Leibovic S, Sanes JN (1992) Organization of the forelimb area in squirrel monkey motor cortex: representation of digit, wrist, and elbow muscles. Exp Brain Res 89: $1-19$

Elwell CE, Cope M, Edwards AD, Wyatt JS, Deply DT, Reynolds EOR (1994) Quantification of adult cerebral hemodynamics by near-infrared spectroscopy. J Appl Physiol 77: 2753-2760

Evarts EV (1968) Relation of pyramidal tract activity to force exerted during voluntary movements. J Neurophysiol 31: $14-27$

Fox PT, Raichle ME (1984) Stimulus rate dependence of regional cerebral blood flow in human striate cortex demonstrated by positron emission tomography. J Neurophysiol 51: 1109-1120

Gemba H, Sasaki K (1987) Cortical fields potentials associated with auditory-initiated hand movements in the monkey. Exp Brain Res 65: 649-657

Hepp-Reymond MC, Husler EJ, Maier MA, Qi HX (1994) Forcerelated neuronal activity in two regions of the primate ventral premotor cortex. Can J Physiol Pharmacol 72: $571-579$ 
Hepp-Reymond MC, Kirkpatrick-Tanner M, Gabernet L, Qi HX, Weber B (1999) Context-dependent force coding in motor and premotor cortical areas. Exp Brain Res 128: 123-133

Hepp-Reymond MC, Wyss UR, Anner R (1978) Neuronal coding of static force in primate motor cortex. J Physiol (Paris) 74: 287-291

Hirth C, Obrig H, Valdueza J, Dirnagl U, Villringer A, (1997) Simultaneous assessment of cerebral oxygenation and hemodynamics during a motor task. A combined near infrared and transcranial Doppler sonography study. Adv Exp Med Biol 411: 471-480

Hoshi Y, Onoe H, Watanabe Y, Andersson J, Bergströme M, Lilija A, Langströme B, Tamura M. (1994) Nonsynchronous behavior of neuronal activity, oxidative metabolism and blood supply during mental tasks in man. Neurosci Lett 172: 129-133

Hoshi Y, Tamura M (1993) Detection of dynamic change in cerebra; oxygenation coupled to neuronal function during mental work in man. Neurosci Lett 150: 5-8

Ingvar DH, Risberg J (1965) Influence of mental activity upon regional cerebral blood flow in man. Apreliminary study. Acta Neurol Scand (Suppl) 14: 183-186

Jenkins IH, Passingham RE, Brooks DJ (1997) The effect of movement frequency on cerebral activation: a positotron emission tomography study. J Neurol Sci 151: 195-205

Kastrup A, Kruger G, Neumann-Haefelin T, Glover GH, Moseley ME (2002) Change of cerebral blood flow, oxygenation, and oxidative metabolism during graded motor activation. NeuroImage 15: 74-82

Kato T, Kamei A, Takahashi S, Ozaki T (1993) Human visual cortical function during photic stimulation monitoring by means of near-infrared spectroscopy. J Cereb Blood Flow Metab 13: 516-520

Kleinschmidt A, Obrig H, Requardt M, Merboldt KD, Dirnagl U, Villringer A, Frahm J (1996) Simultaneous recording of cerebral blood oxygenation changes during human brain activation by magnetic resonance imaging and near-infrared spectroscopy. J Cereb Blood Flow Metab 16: 817-826

Koizumi H, Yamashita Y, Maki A, Yamamoto T, Ito Y, Itagaki H, Kennan R (1999) Higher-order brain function analysis by trans-cranial dynamic near-infrared spectroscopy imaging. $\mathrm{J}$ Biomed Opt 4: 403-413

Lassen NA, Friberg L (1988) Methods for measurement of regional cerebral blood flow. In Olsen J, Edvinsson L eds. Basic Mechanisms of Headache. Elsevier, Copenhagen, 61-68

Lerner A, Shill H, Hanakawa T, Bushara K, Goldfine A, Hallett M (2004) Regional cerebral blood flow correlates of the severity of writer's cramp symptoms. NeuroImage 21: 904-913

Maki A, Yamashita Y, Ito Y, Watanabe E, Mayanagi Y, Koizumi H (1995) Spatial and temporal analysis of human motor activity using noninvasive NIR topography. Med Phys 22: 1997-2005
Meek JH, Firbank M, Elwell CE, Atkinson J, Braddick O, Wyatt JS (1998) Regional hemodynamic responses to visual stimulation in awake infants. Pediatr Res 43: 840-843

Mehagnoul-Schipper DJ, Vloet LCM, Colier WNJM, Hoefnagels WHL, Jansen RWMM (2000) Cerebral oxygenation declines in healthy elderly subjects in response to assuming the upright position. Stroke 31: 1615-1620

Nielsen HBR, Boushel P, Madsen P, Secher NH (1999) Cerebral desaturation during exercise reversed by $\mathrm{O}_{2}$ supplementation. Am J Physiol 277: 1045-1052

Obrig H, Hirth C, Junge Hulsing JG, Doge C, Wolf T, Dirnagl U, Villringer A (1996) Cerebral oxygenation changes in response to motor stimulation. J Appl Physiol 81: 1174-1183

Obrig H, Wenzel R, Kohl M, Horst S, Wobst P, Steinbrink J, Thomas F, Villringer A (2000) Near-infrared spectroscopy: does it function in functional activation studies of the adult brain? Int J Psychophysiol 35: 125-142

Pandya DN, van Hoesen GW, Mesulam M-M (1981) Efferent connections of the cingulated gyrus in the rhesus monkey. Exp Brain Res 42: 319-330

Pardo JV, Fox PT, Raichle ME (1991) Localization of a human system for sustained attention by positron emission tomography. Nature 349: 61-64

Paus T, Petrides M, Evans AC, Meyer E (1993) Role of the human anterior cingulated cortex in the control of oculomotor, manual, and speech responses: a positron emission tomography study. J Neurophysiol 70: 453-469

Porter R, Lemon R (1993) Corticospinal function and voluntary movement. Oxford Science, Oxford, UK, 428

Price C, Wise R, Ramsay S, Friston K, Howard D, Patterson K, Frackowiak R (1992) Regional response difference within the human auditory cortex when listening to words. Neurosci Lett 146: 179-182

Raichle ME, Fiez JA, Videen TO, MacLeod AM, Pardo JV, Fox PT, Petersen SE (1994) Practice-related changes in human brain functional anatomy during nonmotor learning. Cerebral Cortex 4: 8-26

Raichle ME, Grubb RL, Gado MH, Eichling JO, Ter-Pogossian MM (1976) Correlation between regional cerebral blood flow during stereognostic testing in man. Arch Neurol 33: 523-526

Rao SM, Bandettini PA, Binder JR, Bobholz JA, Hammeke TA, Stein EG, Hyde JS (1996) Relationship between finger movement rate and functional magnetic resonance imaging. J Cereb Blood Flow Metab 16: 1250-1254

Rao SM, Binder JR, Bandettini PA, Hammeke TA, Yetkin FZ, Jesmanowicz A, Lisk LM, Morris GL, Mueller WM, Estkowski LD, Wong EC, Haughton VM, Hyde JS (1993) Functional magnetic resonance imaging of complex human movements. Neurology 43: 2311-2318

Roland PE, Larsen B, Lassen NA, Skinhoj E (1980) Supplementary motor area and other cortical areas in organization of voluntary movements in man. J Neurophysiol 43: 118-136 
Roy S, Sherrington S (1890) On the regulation of the blood supply of the brain. J Physiol 11: 85-108

Sabatini U, Chollet F, Rascol O, Celsis P, Rascol A, Lenzi GL, Marc-Vergnes JP (1993) Effect of side and rate of stimulation on cerebral blood flow changes in motor areas during finger movement in humans. J Cereb Blood Flow Metab 13: 639-645

Sadato N, Ibanez V, Deiber M-P, Campbell G, Leonard M, Hallett M (1996) Frequency-dependent changes of regional cerebral blood flow during finger movements. J Cereb Blood Flow Metab 16: 23-33

Sadato N, Ibanez V, Deiber MP, Campbell G, Deiber MP, Le Bihan D, Hallett M (1997) Frequency-dependent changes of regional cerebral blood flow during finger movements: functional MRI compared to Pet. J Cereb Blood Flow Metab 17: 670-679

Sanes JN, Donoghue JP, Thangaraj V, Edelman RR, Warach S (1995) Shared neural substrates controlling hand movements in human motor cortex. Science 268: 1775-1777

Sato KC, Tanji J (1989) Digit-muscle responses evoked from multiple intracortical foci in monkey precentral motor cortex. J Neurophysiol 62: 959-970

Seiz RJ, Roland E, Bohm C, Greitz T, Stone-Elanders S (1990) Motor learning in man: a positron emission tomographic study. Neuroreport 1: 57-60

Siemionow V, Yue GH, Ranganathan VK, Liu JZ, Sahgal V (2000) Relationship between motor activity-related cortical potential and voluntary muscle activation. Exp Brain Res 133: 303-311

Thickbroom GW, Phillips BA, Morris I, Byrnes ML, Mastaglia FL (1998) Isometric force-related activity in sensorimotor cortex measured with functional MRI. Exp Brain Res 121: 59-64

Thckbroom GW, Phillips BA, Morris I, Byrnes ML, Sacco P, Mastaglia FL (1999) Differences in functional magnetic resonance imaging of sensorimotor cortex during static and dynamic finger flexion. Exp Brain Res 126: 431-438 van der Sluijs MC, Colier WNJM, Houston RJF, Oeseburg B (1998) A new and highly sensitive continuous wave near infrared spectrophotometer with multiple detectors. Proc SPIE 3194: 63-72

Vernieri F, Rosato N, Pauri F, Tibuzzi F, Passarelli F, Rossini PM (1999) Near infrared spectroscopy and transcranial Doppler in monohemispheric stroke. Eur Neurol 41: 159-162

Villringer A (1997) Understanding functional neuroimaging methods based on neurovascular coupling. Adv Exp Med Biol 413: 177-193

Villringer A, Planck J, Hock C, Schleinkofer L, Dirnagl U (1993) Near-infrared spectroscopy (NIRS) A new tool to study hemodynamics changes during activation of brain function in human adults. Neurosci Lett 154: 101-104

Wise R, Chollet F, Hadar U, Friston K, Hoffner E, Frackowiak $\mathrm{R}$ (1991) Distribution of cortical neural networks involved in word comprehension and word retrieval. Brain 114: 1803-1817

Zhu HX, Kim GS, Andersen P, Ogawa S, Ugurbil K, Chen W (1998) Simultaneous oxygenation and perfusion imaging study of functional activity in primary visual cortex at different visual stimulation frequency: Quantitative correlation between BOLD and CBF changes. Magn Reson Med 40: 703-711

Received: June 18, 2004

Accepted: February 21, 2005

Correspondence to: Naomi Kuboyama, Graduate School of Human Environment Studies, Kyushu University, Kasuga-koen 6-1, Kasuga, Fukuoka 816-8580, Japan

Phone: +81-92-583-7555 (ext. 7357)

Fax: +81-92-592-2866

e-mail: kuboyama-n@students.ihs.kyushu-u.ac.jp 